\title{
]jfis
}

\section{Fuzzy Mediation Analysis for KOSPI-Related Variables}

\author{
Dae Jong Kim ${ }^{1}$, Yoo Young Koo ${ }^{2}$, and Jin Hee Yoon ${ }^{3}$ \\ ${ }^{1}$ Department of Business Administration, Sejong University, Seoul, Korea \\ ${ }^{2}$ University College, Yonsei University, Incheon, Korea \\ ${ }^{3}$ Department of Mathematics and Statistics, Sejong University, Seoul, Korea
}

\begin{abstract}
Stock prices and bond interest rates are inversely related. The current account plays the most important role in the rise of composite stock index. When the trade surplus increases, stock prices rise sharply. Conversely, when the exchange rate and government bond interest rates increase, the composite stock index decreases. The stock index is influenced by several economic variables, politics, the economy, and investment sentiment. In real situations, such financial variables are mostly fuzzy variables. For example, the Korea Composite Stock Price Index (KOSPI) is recorded based on the closing price. However, the daily KOSPI has many values, such as the open price, low price, and high price; therefore, if only the closing price is used for analysis, only partial information is. To analyze the relationship between KOSPIrelated variables, the KOSPI, stock deposits, government bond interest rates, and foreign security investment data are applied. We investigated the mediated relation of variables, known as mediation analysis. In particular, we implemented fuzzy mediation analysis owing to the ambiguity of given data. In the data analysis, we proposed several fuzzy mediation models using fuzzy transformed data.
\end{abstract}

Keywords: Fuzzy numbers, Fuzzy data, KOSPI, Fuzzy mediation analysis

Received: Feb. 22, 2021

Revised : Mar. 14, 2021

Accepted: Mar. 17, 2021

Correspondence to: Jin Hee Yoon (jin9135@sejong.ac.kr)

(CThe Korean Institute of Intelligent Systems

cCThis is an Open Access article distributed under the terms of the Creative Commons Attribution Non-Commercial License (http://creativecommons.org/licenses/ by-nc/3.0/] which permits unrestricted noncommercial use, distribution, and reproduction in any medium, provided the original work is properly cited.

\section{Introduction}

In data analysis, it is difficult to accurately represent several cases using real numbers. For example, in a survey (for example, a survey of real estate prices), the observed data may be satisfactory, highly satisfactory, or approximately 300 million. This can also be applied to financial data. The daily KOSPI (Korea Composite Stock Price Index) data are recorded using the closing price of the day. However, the closing price cannot fully represent the information of the day; there are numerous variations and fluctuations in a day. The variations and fluctuations can also be considered as a vagueness that cannot be expressed by a real number. To analyze these ambiguous data, we implemented the fuzzy theory introduced by Zadeh [1]. When analyzing the causal relationship between variables based on observed data, we conducted regression analysis. Furthermore, if the observed data included vagueness, the data can be fuzzified to apply fuzzy regression analysis. In this study, we used fuzzy mediation analysis introduced by Yoon [2] to analyze a somewhat complicated fuzzy regression model.

Stock prices and bond interest rates are inversely related. Falling government bond yields increase the stock deposits and funds waiting for stocks; thus, the KOSPI increases immediately. 
The government lowered the key interest rate by $0.5 \%$ owing to the coronavirus disease 2019 (COVID-19) pandemic. The key interest rate in Korea in 2021 is $0.5 \%$; the United States rate is $0 \%$ [3]. This key rate is the rate at which the Federal Reserve and Central Bank lend money to commercial banks. With the COVID-19 pandemic, the interest rates globally have been reduced to save the economy. When the interest rates are lowered, several people increase their stock deposits to buy stocks. As of 2021, the stock deposits of Korea have increased to 60 trillion Korean won. As of January 2021, the KOSPI is 3100 points. In January 2020, it fell from 2600 to 1,400 points in March. It fell by approximately $40 \%$. In February 2021, the KOSPI increased by $120 \%$ to 3100 points. This is the largest increase in the stock index among countries worldwide. If the interest rates are lowered, the stock index and stock deposits increase. In the United States, people have increased their stock deposits by setting the key interest rate to $0 \%$, which raised the US Dow Jones, S\&P500, and Nasdaq to an all-time high [4].

When the interest rate is reduced in this manner, the stock market is revitalized as stock deposits increase. The United States and Korea witnessed a sharp decline in the global economy $(-5 \%)$ due to the COVID-19 pandemic [5]. The governments of each country lowered the interest rates to the maximum in an endeavor to save the economy. In 2021, the stock market rose sharply with the availability of vaccines. The Korean stock market has also risen by $100 \%$ in comparison to March 2020 . Moreover, the stock market of the United States rose significantly. Dow Jones and Nasdaq in the United States are also registering record highs. When the interest rates are lowered, customer deposits increase; this stock deposit is constituted of the rise in the stock market. This is applicable to Korea as well as all countries worldwide. The United States has lowered its key interest rate to $0 \%$ [3]. Accordingly, the government bond interest rate is $0.89 \%$ [5]. This is an indication of consuming instead of depositing in the bank. Naturally, stock deposits, which await funds to buy stocks, increase. When the stock deposits increase, stock investment increases and stock prices rise. The US government has expanded its fiscal policy to increase government spending. As the economy is revitalized, the price of US stocks is increasing significantly. Conversely, as the bond prices in the United States increase, interest rates fall.

The stock and bond interest rates move in opposite directions. Stocks are dangerous goods. When the economy grows, stocks are considerably increased. In March 2020, greatly influenced by the COVID-19 pandemic, the KOSPI fell by $40 \%$ and at the time, the government lowered the interest rate to $0.5 \%$. The interest in the bond and price of the bond moved in reverse [6].

In this study, we analyzed the monthly data over the last 20 years for the KOSPI, stock deposits, government bond interest rates, and foreign security investments. For the values of each variable, if fluctuations are observed even for one month, the closing data or the average of that month cannot fully represent these fluctuations. Therefore, we applied the fuzzy theory to each dataset to reflect the vagueness and fluctuation in each data. In particular, we implemented fuzzy mediation analysis [2] to analyze the causal relationship of variables as well as the mediated variables, which are also called mediators. In Sections 2 and 3, fuzzy mediation analysis and fuzzy KOSPI-related data, respectively, have been discussed, and Section 4 describes data analysis using fuzzy mediation models with fuzzy KOSPIrelated data.

\section{Fuzzy Mediation Analysis}

\subsection{Fuzzy Numbers}

In this section, we introduce some basic concepts of fuzzy numbers. A fuzzy set was first proposed by Zadeh [1] in 1965. A fuzzy number using the fuzzy set is defined as follows:

Definition 1 (Fuzzy numbers). For the fuzzy membership function $\mu_{A}: R \rightarrow[0,1]$ of a fuzzy set $\widetilde{A}, \widetilde{A}$ is a fuzzy number if $\widetilde{A}$ satisfies the following properties:

1) (Normality) There exists $x_{0}$, which satisfies

$$
\mu_{\widetilde{A}}\left(x_{0}\right)=1 .
$$

2) (Fuzzy convexity) For a given $x, y \in R$ and $t \in R$,

$$
\mu_{\widetilde{A}}(t x+(1-t) y) \geq \min \left(\mu_{A}(x), \mu_{A}(y)\right) .
$$

3) (Upper semi-continuity) For any $x_{0} \in R$, if

$$
\mu_{\widetilde{A}}\left(x_{0}\right) \geq \lim _{x \rightarrow x_{0}^{+}} \mu_{\widetilde{A}}(x),
$$

then $\widetilde{A}$ is a fuzzy number.

The $\alpha$-level set of a fuzzy set $\tilde{A}$ is defined by

$$
\widetilde{A_{\alpha}}:=\left\{x \in R \mid \mu_{\tilde{A}}(x) \geq \alpha\right\} .
$$

In addition, the membership function of an L-R fuzzy number $\tilde{A}=\left(a, l_{a}, r_{a}\right)_{L R}$ is defined as follows: 


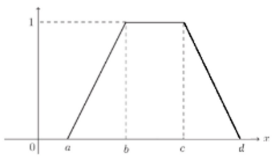

(a)

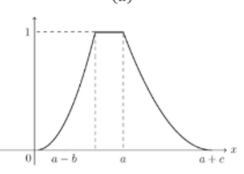

(d)

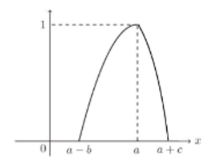

(h) (b)

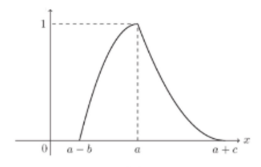

$(e)$

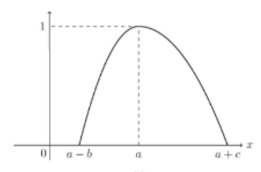

(i)

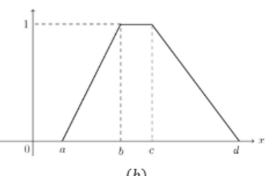

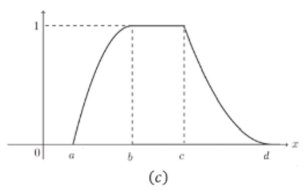

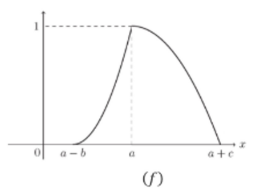

$(f)$

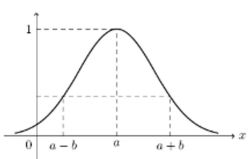

Figure 1. (a-f) Various types of fuzzy numbers.

$$
\mu_{\tilde{A}}(x)= \begin{cases}L_{\tilde{A}}\left(\frac{a-x}{l_{a}}\right) & \text { for } 0 \leq a-x \leq l_{a}, \\ R_{\tilde{A}}\left(\frac{x-a}{l_{a}}\right) & \text { for } 0 \leq x-a \leq r_{a}, \\ 0 & \text { o.w }\end{cases}
$$

where $L_{\tilde{A}}$ and $R_{\tilde{A}}$ are non-increasing functions that satisfy $L_{\tilde{A}}(0)=R_{\tilde{A}}(0)=1$ and $L_{\tilde{A}}(1)=R_{\tilde{A}}(1)=0$. Here, $a$ is called the mode of $\tilde{A} ; l_{a}, r_{a}$ are the left and right spreads, respectively. In particular, $L_{\tilde{A}}$ and $R_{\tilde{A}}$ are linear functions; the fuzzy number $\tilde{A}$ is called a triangular fuzzy number and it is written as $\tilde{A}=\left(l_{a}, a, r_{a}\right)$. Here, $a-l_{a}$ and $r_{a}-a$ are the left and right spreads, respectively. Figure 1 shows the various types of fuzzy numbers.

Based on the extension principle in [1], the following two operations for fuzzy triangular numbers can be defined:

$$
\begin{aligned}
& \tilde{X} \oplus \tilde{Y}=\left(l_{x}+l_{y}, x+y, r_{x}+r_{y}\right), \\
& k \tilde{X}= \begin{cases}\left(k l_{x}, k x, k r_{x}\right), & k \geq 0, \\
\left(k r_{x}, k x, k l_{x}\right), & k<0,\end{cases}
\end{aligned}
$$

where $\tilde{X}=\left(l_{x}, x, r_{x}\right), \tilde{Y}=\left(l_{y}, y, r_{y}\right) \in F_{T}$ for $k \in \mathbb{R}$.

\subsection{Fuzzy Mediation Analysis}

In this section, we introduce the fuzzy mediation analysis proposed in [2].

In data analysis, when analyzing the causal relationship of variables, we sometimes encounter a variable that lies between the cause and effect in a causal chain. This variable is called a mediator (Figure 2). Figure 2 illustrates a conceptual model.

Especially, if the data contain ambiguity, such as "good,"

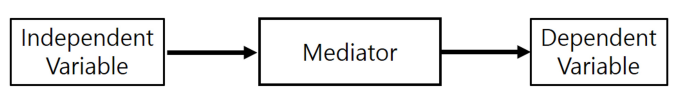

Figure 2. Simple mediation model (conceptual model).

"about 3," or "moderate," it is more reasonable to represent the data using fuzzy numbers. Using these fuzzy data, a fuzzy mediation model can be established [4].

$$
\begin{aligned}
& \tilde{Y}=\beta_{10} \oplus \beta_{11} \tilde{X} \oplus \widetilde{E_{1}}, \\
& \widetilde{M}=\beta_{10} \oplus \beta_{21} \tilde{X} \oplus \widetilde{E_{2}}, \\
& \widetilde{M}=\beta_{10} \oplus \beta_{21} \tilde{X} \oplus \widetilde{E_{2}} .
\end{aligned}
$$

Here, the constant term $\beta_{10}$ is defined by $\beta_{10} \cdot \widetilde{1}$, where $\widetilde{1}=(1$, $1,1)$.

$\beta_{11}$ is the "total effect" of $\tilde{X}$ on $\tilde{Y}, \beta_{21} \beta_{32}$ is the indirect effect of $\tilde{M}$ on $\tilde{Y}, \beta_{31}$ is the direct effect of $\tilde{X}$ on $\tilde{Y}$, and $\beta_{11}=\beta_{31}+\beta_{21} \beta_{32}$.

When there are $k(k>1)$ mediators, the multiple fuzzy mediation model can be estimated as follows:

$$
\begin{aligned}
& \tilde{Y}=\beta_{10} \oplus \beta_{11} \tilde{X} \oplus \widetilde{\varepsilon_{1}}, \\
& \widetilde{M}_{j}=\beta_{20}^{j} \oplus \beta_{21}^{j} \tilde{X} \oplus \widetilde{\varepsilon_{2}^{j}}, \\
& \tilde{Y}=\beta_{30} \oplus \beta_{31} \tilde{X}+\sum_{j=1}^{k} \beta_{32}^{j} \widetilde{M_{j}}+\widetilde{\varepsilon_{3}},
\end{aligned}
$$

where $j=1, \ldots, k$. The total effect can be divided into direct and indirect effects, and there are $k$ indirect effects. To estimate the aforementioned models, we obtained the following results based on least squares estimation and suitable operations [7, 8].

$$
\widehat{\beta}=\left(\widetilde{X}^{t} \diamond \widetilde{X}\right)^{-1} \widetilde{X}^{t} \diamond \widetilde{y}
$$

Here, the operation $\diamond$ implies $\tilde{X} \diamond \tilde{Y}=l_{x} l_{x}+x y+r_{x} r_{y}$, where $\tilde{X}=\left(l_{x}, x, r_{x}\right), \tilde{Y}=\left(l_{x}, y, r_{y}\right)$.

Figure 3 illustrates a statistical model. With the coefficients of the aforementioned models, in Figure 4 can be expressed by

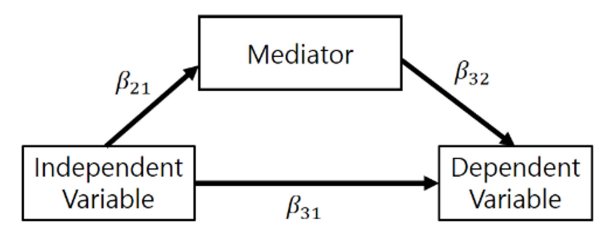

Figure 3. Simple mediation model (statistical model). 


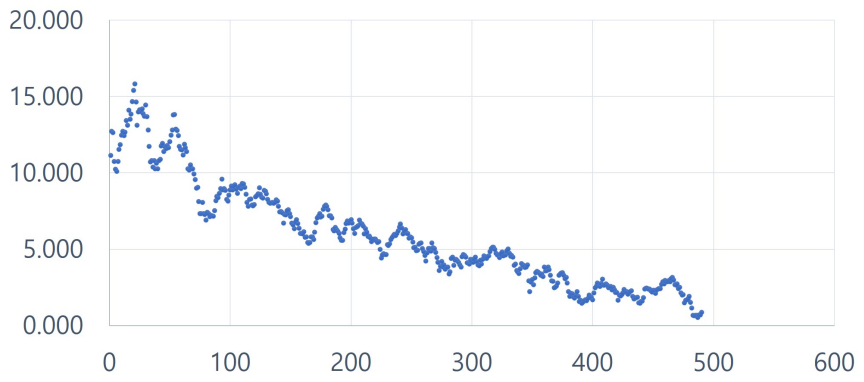

Figure 4. Trend analysis of 10-year US government bonds (1980 to 2020). X-axis is time (month) and Y-axis is interest rate (\%). Bond rates decline over time. (Source: Bank of Korea, http://ecos.bok.or.kr).

the following diagrams in Figure 3.

\section{KOSPI-Related Data}

We investigated four KOSPI-related variables, namely, the government bond rates, foreign security investments, stock deposits, and the KOSPI. The three main factors of investment include profitability, safety, and currency. Foreign investors buy Korean stocks when their interest rates fall. As of 2020, approximately $30 \%$ of all Korean stocks are foreign investments. From the perspective of a foreigner, the economic growth rate of Korea is fast; therefore, the rate of increase in stocks is high. Korea ranks fifth in the world in the manufacturing industry. China, the United States, Japan, and Germany are the only countries with higher manufacturing rankings than Korea. Korea-based Samsung Electronics and Hynix Semiconductor constitute $80 \%$ of memory semiconductors available globally. Foreigners own $55 \%$ of Samsung Electronics, which constitutes $60 \%$ of the global semiconductor memory sector. Superior Korean companies with high foreign ownership have a high growth potential. Foreign investors in Korea make both direct and indirect investments [6]. FDI foreigners invest directly in Korea to build factories and hire Koreans. Indirect investment by foreigners is called FII or foreign portfolio investment. This refers to investing in Korean stocks and bonds. The market capitalization of Korea is 2,000 trillion Korean won, and the amount invested by foreigners is approximately $30 \%$ or 700 trillion Korean won. From the perspective of foreigners, investing in Korea is better than investing in the United States or UK [6]. The United States key interest rate in 2021 is $0 \%$. In terms of US 10-year bonds, it is in the $0.87 \%$ range [3]. A time series can be used to represent the 10-year US government bond interest rate from 1980 to 2020. The entire period consists of approximately 500 months. Bond yields have risen to $15 \%$ in the past; however, they fell
10.000

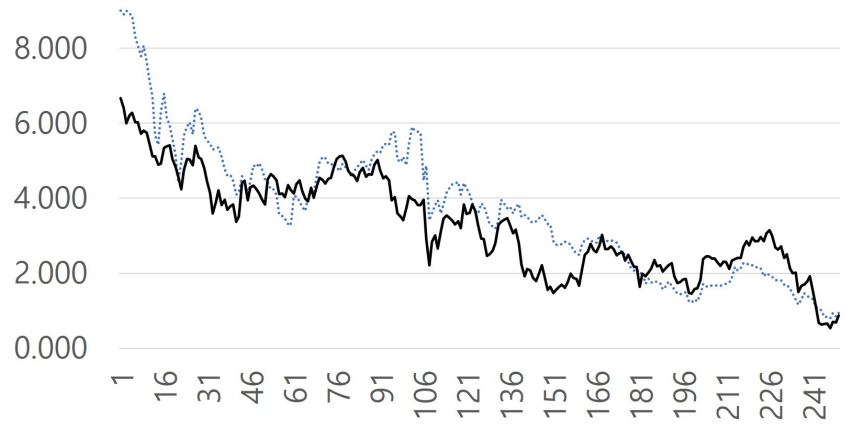

Figure 5. Trends in Korea and US government bonds (2000-2020). Dashed line is 3-year Korean government bonds and solid line is 10 -year US government bonds. X-axis is time (month) and Y-axis is interest rate (\%). Bond rates decline over time. (Source: Bank of Korea, http://ecos.bok.or.kr).

to $0.87 \%$ as of November 2020 [5]. Figure 4 shows the time series of US government bonds.

Empirical analysis has demonstrated that the interest rate of bonds in 2021 will fall for various reasons. There will be a temporary slight rebound, but the long-term trend is expected to continue to decline. This analysis demonstrated a decline in US bond yields over 40 years. We compared the trends of Korean 3-year government bonds and 10-year US government bonds. The government bond interest rate of Korea was the highest at approximately $9 \%$. In 2021, it fell to the 1\% level [5].

The interest rate of Korean government bonds continues to decline along with that of US government bonds. The interest rates on US government bonds were higher than those on Korean government bonds in 2020 [5]. However, in the long run, the 3-year government bond rate of Korea is moving below the US 10-year government bond rate. It can be said that they are almost synchronized and move together. (Figure5)

In 2020, owing to the COVID-19 pandemic, the stock index of Korea witnessed the largest increase. Korea ranks first globally in terms of internet penetration, communication infrastructure construction, educational passion, and college entrance rate. Therefore, the growth potential of Korea is higher than that of any other country [9]. Goldman Sachs selected Korea as the country with the highest per capita national income after the United States. Goldman Sachs found that Korea will become the world's second-largest power by 2050 owing to its excellent education infrastructure and human resources [10] Owing to the COVID-19 pandemic, the key interest rate in both the United States and Europe was 0\%. Thus, foreigners made direct or indirect investments in Korea. If foreign investment 
Table 1. Descriptive statistics

\begin{tabular}{lcccc}
\hline & KOSPI & $\begin{array}{c}\text { Government bond } \\
\text { interest rate }\end{array}$ & Stock deposit $\left(\mathbf{1 0}^{\mathbf{3}} \mathbf{\$}\right)$ & $\begin{array}{c}\text { Foreign securities } \\
\text { investment }\left(\mathbf{1 0}^{\mathbf{1 2}} \mathbf{W}\right)\end{array}$ \\
\hline Average & 1614.7 & 3.50 & 16453440 & 342.2 \\
Median & 1858.8 & 3.59 & 14586897 & 351.1 \\
Standard deviation & 564.2 & 1.50 & 7950863 & 157.2 \\
Minimum value & 504.0 & 0.83 & 7795952 & 65.3 \\
Maximum value & 2533.5 & 6.58 & 56066861 & 657.7 \\
\hline
\end{tabular}

Table 2. Correlation coefficients

\begin{tabular}{lcccc}
\hline & KOSPI & $\begin{array}{c}\text { Government bond } \\
\text { interest rate }\end{array}$ & Stock deposit & $\begin{array}{c}\text { Foreign securities } \\
\text { investment }\end{array}$ \\
\hline KOSPI & 1 & & & \\
Government bond interest rate & -0.742 & 1 & 1 & \\
Stock deposit & 0.715 & -0.802 & 0.814 & 1 \\
\hline Foreign securities investment & 0.952 & -0.835 & & \\
\hline
\end{tabular}

increases, the KOSPI of Korea will increase. Interest rates also directly affect the KOSPI [5].

\section{Data Analysis}

The data used in this study included monthly data from January 2001 to September 2020, where $\mathrm{n}=237$. All statistical analyses were performed using SPSS software, version 25.0, and Python 3.7. The statistical significance can be denoted by p-value $<$ 0.05 . The descriptive statistics of the data used in this study are presented in Table 1. From 2001 to 2020, descriptive statistical analysis was conducted on government bond interest rates, stock deposits, foreign securities investments, and the KOSPI. In technical statistics, the composite stock index averaged 1614 points. The total investment of foreigners in Korean stocks constitute $35 \%$ of market capitalization. Foreigners can make direct or indirect investment in Korean stocks. The security investment of foreigners accounts for $30 \%$ of Korean stock market capitalization [5].

The results of correlation analysis between the variables in this study are summarized in Table 2 .

Foreign security investment is significantly correlated with the KOSPI, and customer deposits or stock deposits are highly correlated at 0.715 . Stock deposits wait for funds to buy stocks. Government bond interest rates are inversely related to the KOSPI. It is -0.74 . This is because when the government bond interest rates are higher, more customers buy bonds rather than stocks. The correlation also shows that the bond market has an
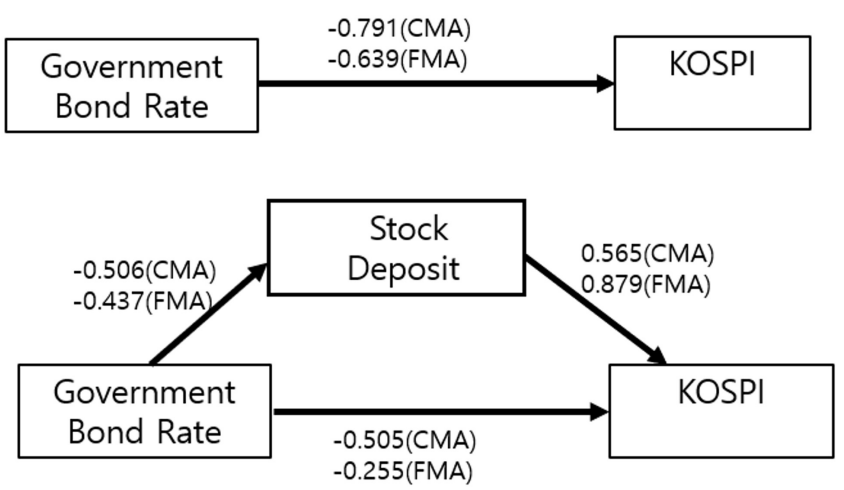

Figure 6. Fuzzy mediation analysis of stock deposit data.

opposite relationship with the stock market.

In addition, all data can be fuzzified, which is more reasonable to understand. The KOSPI, government bond interest rate, and stock deposits are fuzzified using the maximum and minimum of daily data for each month. Foreign security investments are fuzzified using the spreads obtained after taking half of the differences between two adjacent months. After the data are fuzzified, the variables are expressed by fuzzy variables, $\tilde{X}, \tilde{M}$, and $\tilde{Y}$. The relationships between government bond interest $\operatorname{rate}(\tilde{X})$, stock $\operatorname{deposit}(\tilde{M})$, and $\operatorname{KOSPI}(\tilde{Y})$ are illustrated in Figure 6.

In Figure 6, we analyze the causal relationship between the government bond interest rate and KOSPI, and the mediator variable is the stock deposit. According to the results of regression analysis based on classical mediation analysis (CMA), all 
Table 3. Effects for Stock Deposit on KOSPI

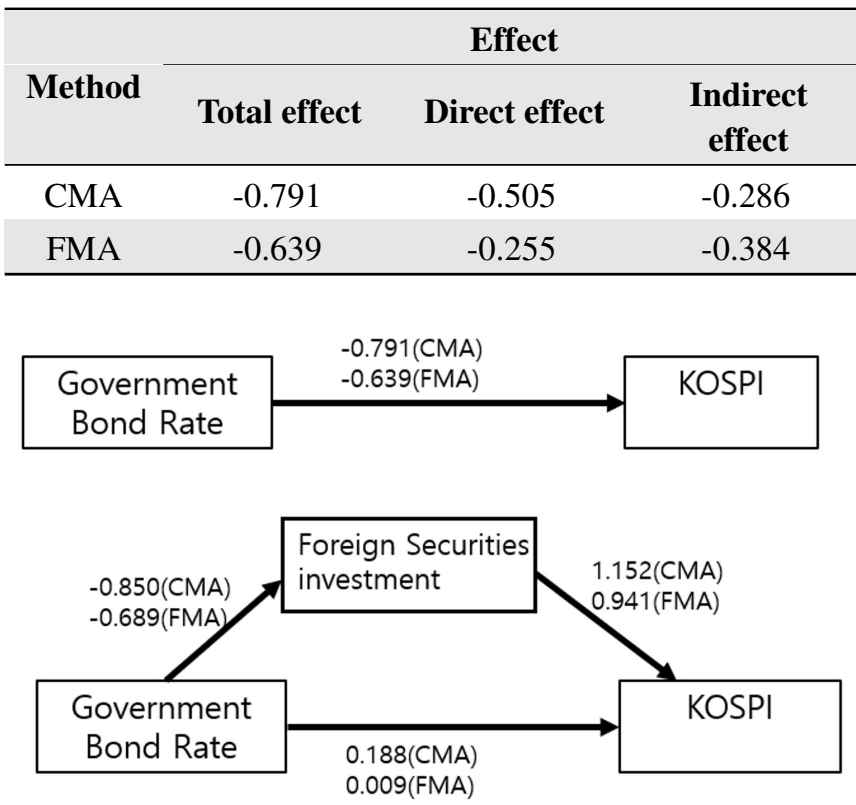

Figure 7. Fuzzy mediation analysis of foreign security investment data.

results were statistically significant ( $\mathrm{p}<0.001)$.

Based on CMA, fuzzy mediation analysis (FMA) is estimated as Table 3.

Here, the total effect can be expressed as the sum of direct and indirect effects.

Total effect $=$ direct effect + indirect effect,

$$
\begin{aligned}
& \text { CMA: }-0.791=(-0.505)+(-0.286), \\
& \text { FMA: }-0.639=(-0.255)+(-0.384) .
\end{aligned}
$$

The results show that when it is analyzed with fuzzy data, the negative direct effect is smaller and the indirect effect is greater than that of CMA. This results in a greater total effect of CMA than that of FMA.

The relationships between the government bond interest rate $(\tilde{X})$, foreign securities investment $(\tilde{M})$, and $\operatorname{KOSPI}(\tilde{Y})$ are illustrated in Figure 7.

Figure 7 shows the causal relationship between the government bond interest rate and KOSPI, with foreign security investment as the mediator variable. According to the results of regression analysis based on CMA, all results were statistically significant $(\mathrm{p}<0.001)$.

The results show that when it is analyzed with fuzzy data, the direct and negative indirect effects are smaller than those of CMA.
Table 4. Effects for foreign security investment on KOSPI

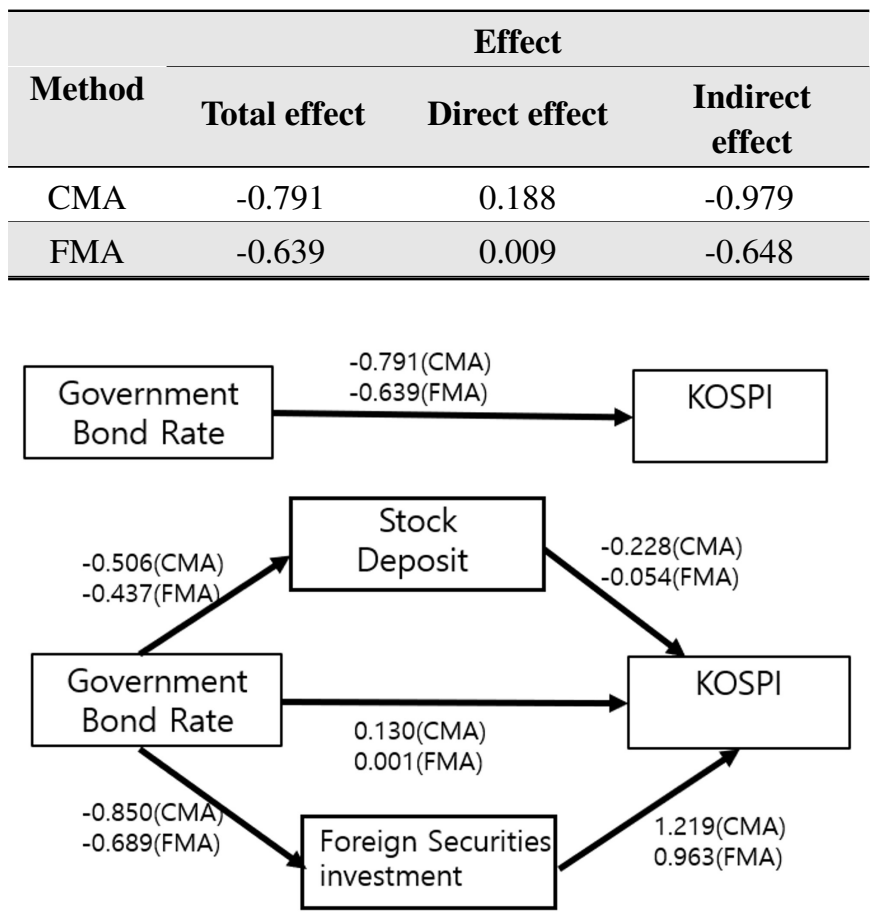

Figure 8 . Fuzzy mediation analysis of stock deposit and foreign security investment data.

Table 4 summarized the parameter estimates of the proposed model.

Here, the total effect can be expressed as the sum of direct and indirect effects.

Total effect $=$ direct effect + indirect effect,

$$
\begin{aligned}
& \text { CMA: }-0.791=0.188+(-0.979), \\
& \text { FMA: }-0.639=0.009+(-0.648) .
\end{aligned}
$$

The relationships between the government bond interest rate $(\tilde{X})$, foreign security investment $(\tilde{M})$, stock deposit $(\tilde{M})$, and $\operatorname{KOSPI}(\tilde{Y})$ are illustrated in Figure 8.

Figure 8 shows a mediation model for multiple mediators. Here, the mediator variables include the stock deposits and foreign security investments. According to the results of regression analysis based on CMA, all results were statistically significant $(\mathrm{p}<0.001)$.

Table 5 lists the parameter estimates for the proposed model. Here, the total effect can be expressed as the sum of direct and indirect effects. In this model, the indirect effect was divided into two parts.

Total effect $=$ direct effect + indirect effect, 
Table 5. Effects for stock deposit and foreign security investment on KOSPI

\begin{tabular}{cccc}
\hline Method & \multicolumn{3}{c}{ Effect } \\
\cline { 2 - 4 } & Total effect & Direct effect & $\begin{array}{c}\text { Indirect } \\
\text { effect }\end{array}$ \\
\hline CMA & -0.791 & 0.130 & $0.115,-1.036$ \\
\hline FMA & -0.639 & 0.001 & $0.024,-0.664$ \\
\hline
\end{tabular}

$$
\begin{aligned}
& \text { CMA: }-0.791=0.130+0.115+(-1.036), \\
& \text { FMA: }-0.639=0.001+0.024+(-0.384) .
\end{aligned}
$$

The results showed that when it is analyzed with fuzzy data, the direct and negative indirect effects are smaller than those of CMA. As evident from the aforementioned results, CMA and FMA yielded similar but slightly different results. This shows how the results can be distorted when ambiguous information is ignored and data are analyzed using only summarized information.

\section{Conclusion}

When governments reduce the interest rates, money is channeled to the stock market. In this process, there are some financial variables that lie in this causal relationship. KOSPI data and several KOSPI-related data were used to analyze this relationship in this study. If the interest rate decreases, the stock deposit and foreign security investment increase, which results in the increase of KOSPI. This procedure can be analyzed using a mediation model to explain this complex causal relationship. Especially, when data cannot be represented precisely, the fuzzy theory can be applied. In this study, we proposed a fuzzy mediation model for KOSPI-related variables because such data contain vague information. We performed data analysis using four KOSPI-related variables, namely, the government bond interest rates, stock deposits, foreign security investments, and KOSPI. After fuzzifying the four variables, fuzzy mediation analysis was applied. From the results, it was confirmed that the effect of the government bond interest rate on KOSPI is not just a direct effect. Data analysis further confirmed that the stock deposit and foreign security investment can indirectly affect the KOSPI data. In future studies, more complicated models that involve more variables will be used based on various types of fuzzy mediation and fuzzy moderation models.

\section{Conflict of Interest}

No potential conflict of interest relevant to this article was reported

\section{References}

[1] L. A. Zadeh, "Fuzzy sets," Information and Control, vol. 8, no. 3, pp. 338-353, 1965. https://doi.org/10.1016/S00199958(65)90241-X

[2] J. H. Yoon, "Fuzzy mediation analysis," International Journal of Fuzzy Systems, vol. 22, no. 1, pp. 338-349, 2020. https://doi.org/10.1007/s40815-019-00727-6

[3] Countryeconomy.com, "US Federal Reserve Bank key rates," 2020, Available https://countryeconomy.com/keyrates/usa.

[4] Bloomberg, "title of news article," 2021, Available http: //www.bloomberg.com/news

[5] Bank of Korea, "Economic statistics system," 2020, Available http://ecos.bok.or.kr/

[6] Korean Statistical Information Service, "title of news article,” 2021, Available https://kosis.kr/statisticsList

[7] J. H. Yoon and S. H. Choi, "Fuzzy least squares estimation with new fuzzy operations," in Synergies of Soft Computing and Statistics for Intelligent Data Analysis. Heidelberg, Germany: Springer, 2013, pp. 193-202. https://doi.org/10.1007/978-3-642-33042-1_21

[8] J. H. Yoon and P. Grzegorzewski, "On optimal and asymptotic properties of a fuzzy L2 estimator," Mathematics, vol. 8, no. 11, article no. 1956, 2020. https://doi.org/10. 3390/math8111956

[9] Yonhap News, “'Korea has made a difference' ... Main institutions raise their growth rate forecast this year," 2021, Available https://www.yna.co.kr/view/ AKR20210126166300002

[10] Korea Economic Daily, "Korea's second largest GDP per capita in 2050," 2011, Available https://www.hankyung. com/international/article/2011052023431, 


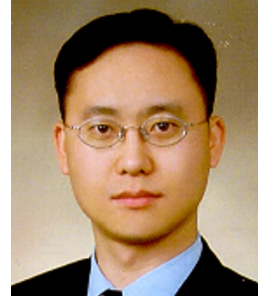

Dae Jong Kim received his B.A. from Hankuk University of Foreign Studies, MBA in economics from Korea University, Ph.D. in economics from Sogang University, Korea. He is currently a faculty in the department of business school at Sejong University, Seoul, Korea. He is Present, Korea Institute for Business and Economics and is listed on the Marquis Who's Who. His research interests include fuzzy regression analysis, fuzzy time series, optimization, intelligent systems, and applied economics.

E-mail:

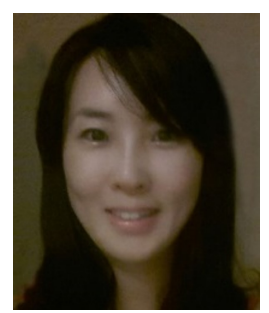

Jin Hee Yoon received her B.S., M.S., and $\mathrm{Ph} . \mathrm{D}$. degrees in mathematics from Yonsei University, Korea. She is currently a faculty member in the department of mathematics and statistics at Sejong University, Seoul, Korea. Her research interests include fuzzy regression analysis, fuzzy time series, optimization, intelligent systems, and machine learning. She is a board member of the Korean Institute of Intelligent Systems (KIIS) and has been working as an associate editor, guest editor, and editorial board member of several journals, including SCI and SCIE. In addition, she has been working as an organizer and committee member of several international conferences.

E-mail:

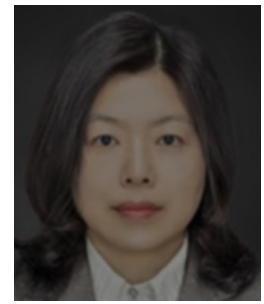

Yoo Young Koo received her B.S., M.S., and $\mathrm{Ph} . \mathrm{D}$. degrees in Mathematics from Yonsei University, Korea. She is currently a faculty member at the University College of Yonsei University, Incheon, Korea. Her research interests include statistical analysis, data analysis, machine learning, and deep learning. E-mail: 